\title{
PRIMARNA I SEKUNDARNA REGULACIJA SNAGE NA BLOKOVIMA TENT B1 I B2 PROMENOM PROTOKA NAPOJNE VODE KROZ DODATNI EKONOMAJZER
}

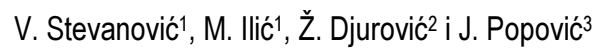 \\ 1 Univerzitet u Beogradu, Mašinski fakultet, Kraljice Marije 16, 11120 Beograd \\ 2Univerzitet u Beogradu, Elektrotehnički fakultet, Bulevar kralja Aleksandra 73, 11120 Beograd \\ 3Zavod za intelektualnu svojinu, Knjeginje Ljubice 5, 11000 Beograd \\ Originalni naučni rad \\ DOI: 10.5937/termoteh
}

Na parnim kotlovima blokova B1 i B2 Termoelektrane „Nikola Tesla B“ je tokom prve faze kapitalnog remonta ugrađen dodatni ekonomajzer, sledstveno 2012. $i$ 2016. godine. Dodatni ekonomajzer se napaja vodom pomoću posebne linije sa potisa napojne pumpe i paralelno je povezan sa delom osnovnog ekonomajzera. Napojna voda se većim delom šalje ka zagrejačima visokog pritiska (ZVP) $u$ okviru osnovne napojne linije, dok se manji deo dovodi do dodatnog ekonomajzera. Dodatni ekonomajzer je povećao stepen korisnosti bloka za preko 0,5 procentnih poena, što omogućava proizvodnju sa oko $10 \mathrm{MW}$,zelene“ električne snage na račun iskorišćenja otpadne toplote dimnih gasova. Pored ovih značajnih energetskih, pratećih ekoloških i finansijskih efekata, ugradnja dodatnog ekonomajzera omogućava i primarnu i sekundarnu regulaciju snage. Povećanjem protoka napojne vode kroz dodatni ekonomajzer smanjuje se protok napojne vode kroz zagrejače visokog pritiska, sledstveno se smanjuje oduzimanje pare nakon ekspanzije u turbini visokog pritiska i oduzimanje na turbini srednjeg pritiska, a samim tim se povećava snaga turbine. U radu su prikazani postupak $i$ rezultati numeričke simulacije promene snage parnih blokova B1 $i$ B2 sa promenom protoka napojne vode kroz dodatni ekonomajzer. Protok napojne vode kroz dodatni ekonomajzer se sa početne vrednosti, koja iznosi $25 \%$ od protoka vode koja se dovodi isparivaču kotla, povećava na $40 \%$ za 15 s. Dobijeni rezultati pokazuju da se usled smanjenja protoka napojne vode kroz ZVP smanjuje njihova toplona snaga za oko 20\%. Smanjena kondenzacija dovodi do povećanja pritisaka na parnoj strani ZVP, što smanjuje oduzimanje pare iz turbine. Usled smanjenog oduzimanja, povećava se protok kroz turbinu srednjeg i turbinu niskog pritiska, tako da se ukupna snage turbine povećava za približno $10 \mathrm{MW}$. Brzina promene temperature metala cevi ZVP je u dozvoljenim granicama. Dobijeni rezultati pokazuju da se promenom protoka napojne vode kroz dodatni ekonomajzer može ostvariti primarna i sekundarna regulacija snage blokova, pri čemu se ne menjaju pritisak, temperatura i protok sveže pare.

Ključne reči: parni blok, ekonomajzer, zagrejači visokog pritiska, oduzimanje pare, snaga turbine.

UVOD

Na parnim kotlovima blokova B1 i B2 Termoelektrane „Nikola Tesla B“, tokom prve faze kapitalnog remonta, ugrađen je dodatni ekonomajzer. Toplotna šema bloka sa dodatnim ekonomajzerom obeleženim sa ECO1A prikazana je na Slici 1. ECO1A se napaja posebnom linijom napojne vode sa potisa napojne pumpe. Ugradnjom 
ekonomajzera ECO1A vrši se preraspodela protoka napojne vode sa potisa napojne pumpe - manji deo se vodi u ekonomajzer EC01A, dok se veći deo šalje u zagrejače visokog pritiska (ZVP) u osnovnoj napojnoj liniji [1]. ZVP su na Slici 1 obeleženi sa ZVP 6, ZVP 7 i ZVP 6bis. Kako su postojeće dve grane ZVP identične i paralelno vezane, može se usvojiti da se ukupni protok napojne vode podjednako raspodeljuje. Prema tome, usvajanjem da je protok jednak polovini ukupnog protoka napojne vode u osnovnoj napojnoj liniji, dovoljno je razmatrati samo jednu granu ZVP. ZVP u okviru jedne grane su vezani redno po toku napojne vode. U ZVP 6bis napojna voda se zagreva hladjenjem pare koja se dovodi iz neregulisanog oduzimanja na turbini srednjeg pritiska (TSP). U ZVP 7 predaja toplote napojnoj vodi se vrši kondenzacijom pare koja se dovodi iz neregulisanog oduzimanja na izlazu iz turbine visokog pritiska (TVP). U ZVP 6, u koji se uvodi još uvek pregrejana para iz zagrejača ZVP 6bis i kondenzat iz slivnog rezervoara zagrejača ZVP 7, predaja toplote napojnoj vodi, takodje, se vrši kondenzacijom. Kondenzat iz zagrejača ZVP 6 se sakuplja u pripadajućem slivnom rezervoaru i odatle preko kondenzatne pumpe vodi u napojni rezervoar.

Pored značajnih energetskih, ekoloških i finansijskih efekata, ekonomajzer EC01A omogućava i primarnu i sekundarnu regulaciju snage bloka, za kojom se javlja potreba pri promeni opterećenja električne mreže. Primarna regulacija snage se aktivira 15 -30s nakon nastajanja poremećaja u mreži. Tokom 30s rada primarne regulacije vrši se uključivanje sekundarne regulacije. Nakon $15 \mathrm{~min}$ rada sekundarnu zamenjuje tercijarna regulacija, koja nije od interesa u ovom radu pošto obuhvata uključivanje postrojenja za vršna opterećenja [2]. Pri promeni snage bloka potrebno je sagledati i odgovarajuća termomehanička opterećenja [3].

$\mathrm{U}$ svetlu primarne i sekundarne regulacije u ovom radu je razmatrano povećanje snage parnih blokova B1 $\mathrm{i}$ B2 sa promenom protoka napojne vode kroz ECO1A koje se odvija na sledeći način. Pri povećanju protoka napojne vode kroz ECO1A dolazi do smanjenja protoka napojne vode kroz ZVP, sledstveno se smanjuje oduzimanje pare nakon ekspanzije u turbini visokog pritiska i oduzimanje na turbini srednjeg pritiska, te se usled povećanog protoka kroz turbine povećava njihova snaga.

\section{FIZIČKI MODEL ZAGREJAČA VISOKOG PRITISKA}

Fizički model zagrejača visokog pritiska je prikazan na Slici 2. Model je razvijen na bazi sledećih pretpostavki. Parna strana ZVP 6 i ZVP 7, koja obuhvata parni prostor samih zagrejača i odgovarajuće rezervoare slivnih pumpi, nalazi se u uslovima saturacije. Obzirom na jedinstvenu temperaturu sa parne strane, u ZVP 6 i ZVP 7 je neophodno izvršiti diskretizaciju samo cevnog snopa (zid cevi i pripadajući vodeni prostor). Sa druge strane, u slučaju ZVP 6bis, gde je potrebno pratiti hladjenje pregrejane pare, i parni prostor mora biti diskretizovan.

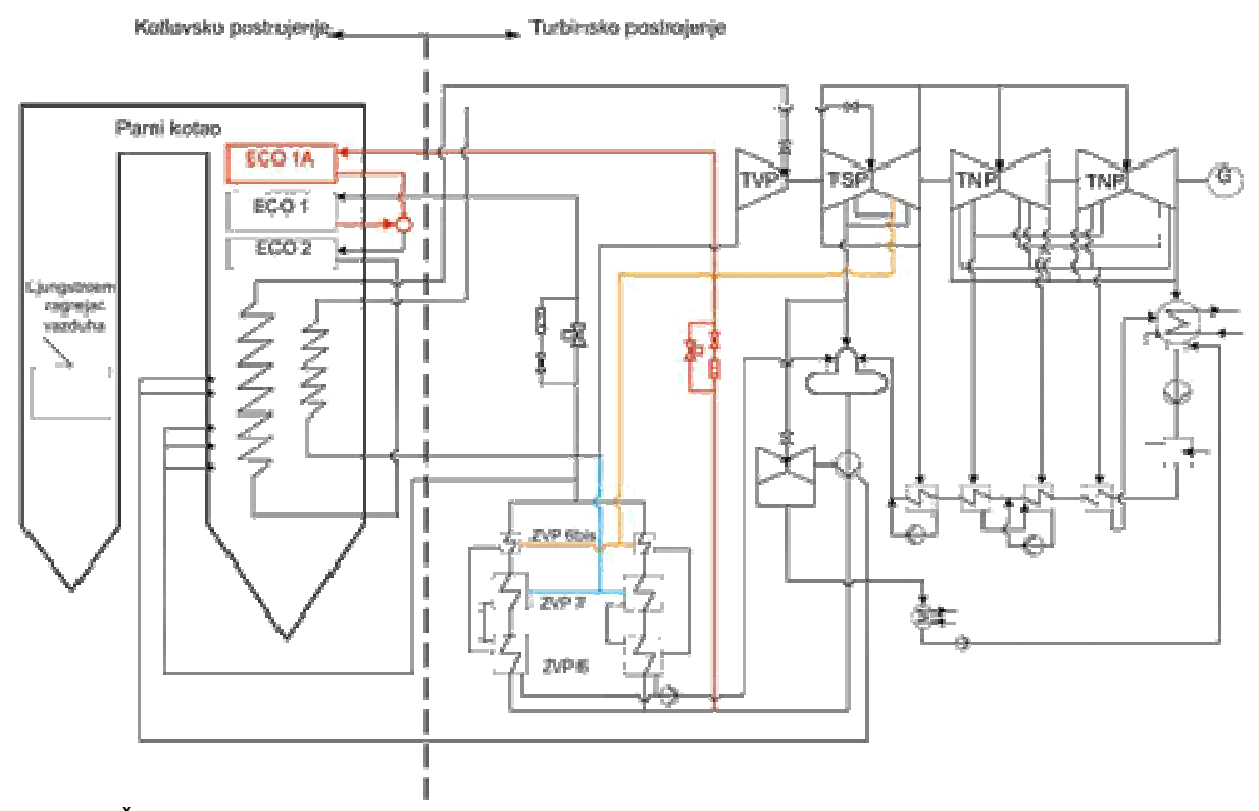

Slika 1: Šema bloka B1/B2 u Termoelektrani „Nikola Tesla B“ sa dodatnim ekonomajzerom ECO 1A 


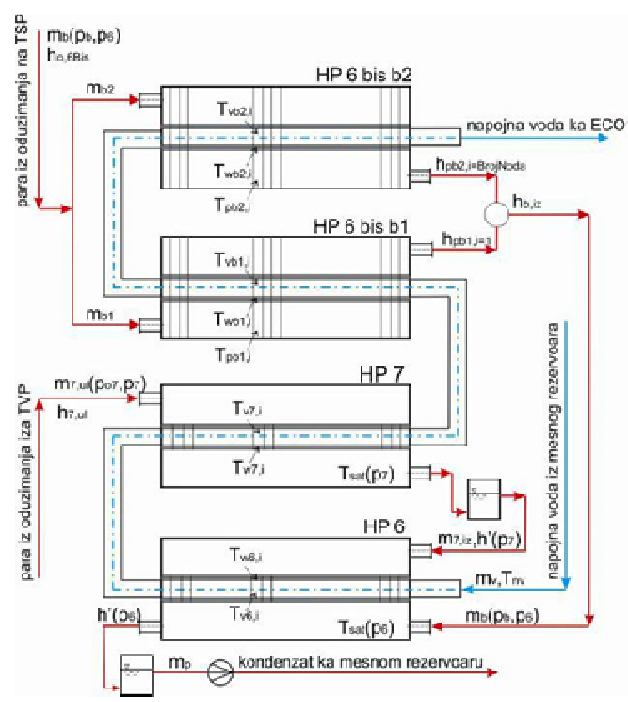

Slika 2: Šematski prikaz fizičkog modela zagrejača visokog pritiska
Kako se u ZVP 6bis para uvodi sa strane gde se nalazi vrh $U$ cevi, ovaj zagrejač je podeljen na dva dela (ZVP 6bis b1 i ZVP 6bis b2) koji su sa vodene strane vezani redno, dok sa parne strane imaju nezavisne ulaze. ZVP 6bis b1 obuhvata prostor sa granom $U$ cevi koja je sa vodene strane vezana na izlaz iz ZVP 7, dok ZVP 6bis b2 obuhvata prostor sa granom $U$ cevi čiji izlaz je sa vodene strane vezan na ulaz u ekonomajzer EC01. Pretpostavljeno je da se para na izlazu iz ZVP 6bis b1 i b2 meša i na taj način dobijena entalpija pare je usvojena kao entalpija pare na izlazu iz ZVP 6 bis.

Za svaki od pomenuta četiri zagrejača je usvojen isti broj kontrolnih zapremina (obeležen sa BrojNoda). Numeracija kontrolnih zapremina je usvojena tako da prati vodeni tok: prva kontrolna zapremina $(i=1)$ nalazi se neposredno na ulazu napojne vode, dok se poslednja (i=BrojNoda) nalazi neposredno pre izlaza iz zagrejača.

\section{MATEMATIČKI MODEL ZAGREJAČA VISOKOG PRITISKA}

\section{Odredjivanje distribucije temperatura u prelaznom režimu rada ZVP}

Bilans energije za zid cevi u $i$-toj kontrolnoj zapremini zagrejača ZVP 6 i ZVP 7 (j= 6, 7) u kojima je temperatura pare jednaka temperaturi saturacije za dati pritisak $\left(T_{\text {sat }}(p j)\right)$ je dat sa:

$$
\left(M_{C}\right)_{w j, i} \frac{d T_{w j, i}}{d t}=K_{p j, i} \cdot\left(T_{s a t}\left(p_{j}\right)-T_{w j, i}\right)-K_{v j, i} \cdot\left(T_{w j, i}-T_{v j, i}\right)
$$

dok je u zagrejačima ZVP 6bis b1 i ZVP 6bis b2 ( $j=$ b1, b2 ) u kojima struji pregrejana para:

$$
\left(M_{C}\right)_{w j, i} \frac{d T_{w j, i}}{d t}=K_{p j, i} \cdot\left(T_{p j, i}-T_{w j, i}\right)-K_{v j, i} \cdot\left(T_{w j, i}-T_{v j, i}\right)
$$

$U$ gornjim jednačinama $d T_{w} / d t$ je promena temperature zida cevi sa vremenom, $T_{p}$ predstavlja temperaturu pregrejane pare, $M_{w}$ je masa zida cevi, a $c_{w}$ je specifična toplota materijala cevi.

Koeficijenti $K_{p}$ i $K_{v}$ su odredjeni kao što je prikazano u donjem tekstu.

Zagrevanje napojne vode u i-toj kontrolnoj zapremini zagrejača $j(j=6,7, b 1, b 2)$ je formulisano sledećom bilansnom jednačinom:

$$
\left(M_{C}\right)_{v j, i} \frac{d T_{v j, i}}{d t}=K_{v j, i} \cdot\left(T_{w j, i}-T_{v j, i}\right)-m_{v} c_{p v j, i} \cdot\left(T_{v j, i}-T_{v j, u l, i}\right)
$$

gde je $d T_{v} / d t$ promena temperature napojne vode sa vremenom, $M_{v}$ masa napojne vode, a $C_{p v}$ specifična toplota napojne vode. Protok napojne vode $m_{v}=m_{v}(t)$ je zadat kao vremenska funkcija.

Tabela 1: Temperatura napojne vode $T_{v j}, u l, i$, na ulazu u kontrolnu zapreminu i zagrejača $j$

\begin{tabular}{|l|c|c|c|c|}
\hline & $j=6$ & $j=7$ & $j=b 1$ & $j=b 2$ \\
\hline$i=1$ & $T_{n v}(t)$ & $T_{v j=6, i=B r o j}$ Noda & $T_{v j=7, i=\text { Broj Noda }}$ & $T_{v j=b 1, i=\text { Broj Noda }}$ \\
\hline$i=2$, BrojNoda & \multicolumn{5}{|c|}{$T_{v j, i-1}$} \\
\hline
\end{tabular}

Temperatura vode na ulazu u kontrolnu zapreminu je odredjena kao što je prikazano u Tabeli 1, gde je $T_{n v}(t)$ temperatura napojne vode na ulazu $u$ zagrejač visokog pritiska ZVP 6.

Hlađenje pregrejane pare u prvom 
(j=b1) i drugom ( $j=b 2)$ delu zagrejača ZVP 6bis je opisano sledećim bilansnim jednačinama:

$$
M_{p j, i} \frac{d h_{p j, i}}{d t}=m_{p j} \cdot\left(h_{p j, u l, i}-h_{p j, i}\right)-K_{p j, i} \cdot\left(T_{p j, i}-T_{w j, i}\right)
$$

gde $d h_{p} / d t$ predstavlja promenu specifične entalpije pregrejane pare sa vremenom, a $M_{p}$ označava masu pare. Temperatura pregrejane pare je računata iz $T_{p j, i}=T_{p}\left(p_{b}, h_{p j, i}\right)$, gde $p_{b}$ predstavlja pritisak pare u zagrejaču ZVP 6bis. Usvojeno je da se maseni protok pregrejane pare kroz ZVP 6bis, $m_{b}$, podjednako raspodeljuje izmedju prvog i drugog dela zagrejača: $m_{p b 1}=m_{p b 2}=0,5 m_{b}$. Entalpija pare na ulazu u kontrolnu zapreminu je odredjena kao:

$$
h_{p b 1, u l, i}=\left\{\begin{array}{lll}
h_{p b 1, i+1,} & z a & i<\text { BrojNoda } \\
h_{o, 6 B i s,} & z a & i=\text { BrojNoda }
\end{array} \quad h_{p b 2, u l, i}=\left\{\begin{array}{lll}
h_{p b 2, i+1,} & z a & i>1 \\
h_{o, 6 B i s,} & z a & i=1
\end{array}\right.\right.
$$

gde je $h_{0,6 B i s}$ entalpija pare na ulazu u ZVP 6bis koja je jednaka entalpiji pare na oduzimanju turbine srednjeg pritiska za zagrejač ZVP 6bis.

Koeficijenti $K_{p j, i}$ i $K_{v j, i}$ u gornjim jednačinama su odredjeni iz:

$$
K_{p j, i}=\kappa_{p j, i} \frac{N_{c j} L_{c j}}{\text { BrojNoda }} \quad K_{v j, i}=\kappa_{v j, i} \frac{N_{c j} L_{c j}}{\text { BrojNoda }}
$$

gde je $N_{c}$ broj cevi, $L_{c}$ dužina cevi, dok $K_{p}$ i $\kappa_{v}$ predstavljaju odgovarajuće koeficijente prolaženja toplote.

Koeficijent prolaženja toplote sa pare do sredine zida cevi je odredjen iz:

$$
\kappa_{p j, i}=\frac{1}{\frac{1}{\pi D_{s j} \alpha_{p j, i}}+\frac{1}{2 \pi \lambda_{w}} \operatorname{Ln} \frac{D_{s j}}{0,5\left(D_{s j}+D_{u j}\right)}}
$$

gde $\alpha_{p}$ predstavlja koeficijent prolaženja toplote sa parne strane, $\lambda_{w}$ je toplotna provodljivost zida cevi, dok $D_{s}$ i $D_{u}$ stoje za spoljašnji i unutrašnji prečnik cevi.

U slučaju zagrejača ZVP6 i ZVP7 koeficijent prelaženja toplote sa parne strane je jednak koeficijentu prelaženja toplote pri kondenzaciji suvozasićene pare na spoljašnjoj površini cevi, $\alpha_{p}=\alpha_{c}$ koji je odredjen na osnovu sledećeg izraza [4]:

$$
\frac{\alpha_{c}}{\lambda_{c}}\left(\frac{v_{c}^{2}}{g}\right)^{\frac{1}{3}}=\frac{\operatorname{Re}}{2300+41 \operatorname{Pr}_{c}^{-0,25}\left(\operatorname{Re}^{0,75}-89\right)\left(\frac{\operatorname{Pr}_{c}}{\operatorname{Pr}_{w}}\right)^{0,25}}
$$

gde su Re Reynolds-ov broj, $\lambda_{c}$ toplotna provodljivost kondenzata, $v_{c}$ kinematska viskoznost kondenzata, $g$ ubrzanje sile Zemljine teže, $\mu_{c}$ dinamička viskoznost kondenzata, $q$ srednja vrednost toplotnog fluksa, $P r_{c}$ Prandtl-ov broj kondenzata i $P r_{w}$ Prandtl-ov broj kondenzata za temperaturu zida cevi.

Koeficijent prelaza toplote sa pare na zid cevi u zagrejačima ZVP 6bis b1 i b2, u kojima se vrši strujanje pregrejane pare duž snopa cevi, odredjen je iz:

$$
\alpha_{p}=\alpha_{s}=\frac{N u \cdot \lambda_{p}}{D_{h}}
$$

gde je $\lambda_{p}$ toplotna provodljivost pregrejane pare i $D_{h}$ hidraulički prečnik. Nusselt-ov broj je računat iz [5]:

$$
\frac{N u}{N u_{t}}=0,855\left[\sqrt{\frac{2 \sqrt{3}}{\pi}} \frac{s_{b}}{D_{s b}}+1\right]^{0,2122}
$$


gde je $N u_{t}=0,02087 R e^{0,7878}$. Reynolds-ov broj je određen iz $\mathrm{Re}=u_{p} D_{h} / v_{p}$, gde $u_{p}$ predstavlja brzinu pare, a $v_{p}$ je kinematična viskoznost pare. Hidraulični prečnik je dat sa $D_{h} / D_{h e}=\sqrt{2 \sqrt{3} / \pi} s / D_{s}+1$, gde je $s$ korak cevi, a $D_{h e}=D_{s}\left[\sqrt{2 \sqrt{3} / \pi} s / D_{s}-1\right]$ hidraulički prečnik ekvivalentnog anulusa.

Koeficijent prolaženja toplote određen je iz:

$$
\kappa_{v j, i}=\frac{1}{\frac{1}{\pi D_{u j} \alpha_{v j, i}}+\frac{1}{2 \pi \lambda_{w}} \operatorname{Ln} \frac{0,5\left(D_{s j}+D_{u j}\right)}{D_{u j}}}
$$

Koeficijent prelažeja toplote sa unutrašnjeg zida cevi ma vodu za sve zagrejače dat je sa:

$$
\alpha_{v}=\frac{N u \cdot \lambda_{v}}{D_{u}}
$$

gde je $\lambda_{w}$ koeficijent toplotne provodljivosti vode. Nusselt-ov broj je računat iz sledeće relacije [6]:

$$
N u=0,021 \varepsilon_{1} \operatorname{Re}^{0,8} \operatorname{Pr}^{0,43}\left(\frac{\operatorname{Pr}}{\operatorname{Pr}_{w}}\right)^{0,11}
$$

gde je $\varepsilon_{1}=1,0$ popravni koeficijent za $L_{d} D_{u}>50$

Modeliranje dinamike dvofazne mešavine na parnoj strani zagrejača ZVP 6 i ZVP 7

Promena mases a vremenom u parnom prostoru zagrejača, određena je iz bilansa protoka na ulazu i izlazu:

$$
\frac{d M_{j}}{d t}=\sum_{i} m_{u l, i}-\sum_{k} m_{i z, k}
$$
gde je za ZVP 6: $\sum_{i} m_{u l, i}-\sum_{i z, k} m_{i, i z}+m_{b}-m_{p}$, dok je za ZVP 7: $\sum_{i} m_{u l, i}-\sum_{k} m_{i z, k}=m_{7, u l}-m_{7, i z}$.
Formulisanje masehih protoka je prikazano u donjem tekstu.

Bilans energije za dvofaznu mešavinu koja se nalazi u parnom prostoru zagrejača je dat sledećom jednačinom:

$$
\frac{d H_{j}}{d t}-V_{j} \frac{d p_{j}}{d t}=\sum_{i} m_{u l, i} h_{u l, i}-\sum_{k} m_{i z, k} h_{i z, k}-Q_{j}
$$

Odvedena količina toplote po jedinici vremena računata je iz:

$$
Q_{j}=\sum_{i=1}^{\text {BrojNoda }} K_{p j, i}\left(T_{s a t}\left(p_{j}\right)-T_{w j, i}\right)
$$

Maseni protoci pregrejane pare na turbinskim oduzimanjima su odredjeni na sledeći način. Protok pare iz oduzimanja na turbini srednjeg pritiska je jednak protoku kroz zagrejač ZVP 6bis koji je dobijen iz:

$$
m_{b}=\sqrt{\frac{p_{b}-p_{6}}{\zeta_{b}}}
$$

dok je protok pare iz oduzimanja iza turbine visokog pritiska:

$$
m_{7, u l}=\sqrt{\frac{p_{o 7}-p_{7}}{\zeta_{7, u l}}}
$$

gde su $\zeta_{b} \mathrm{i} \zeta_{7, u l}$ koeficijenti hidrauličkog otpora odgovarajućih parovoda. 
Maseni protok kondenzata na izlazu iz ZVP 7 je određen intenzitetom kondenzacije i računat kao:

$$
m_{7, i z}=\frac{Q_{7}}{h_{7, u l}-h^{\prime}\left(p_{7}\right)}
$$

Maseni protok kroz kondenzatnu pumpu je određen na bazi sledećih razmatranja. U zagrejač ZVP 6 utiče dvofazna mešavina nastala mešanjem pregrejane pare iz zagrejača ZVP 6bis i kondenzata iz zagrejača ZVP 7. Entalpija ove mešavine je:

$$
h_{6, u l}=\frac{m_{b} h_{b, i z}+m_{7, i z} h^{\prime}\left(p_{7}\right)}{m_{b 1}+m_{b 2}}
$$

gde je entalpija pare na izlazu:

$$
h_{6, i z}=\frac{m_{b} h_{b, i=1}+m_{b 2} h_{b 2, i=\text { BrojNoda }}}{m_{b 1}+m_{b 2}}
$$

Koristeći stepen suvoće mešavine:

$$
x_{6, u l}=\frac{h_{6, u l}-h^{\prime}\left(p_{6}\right)}{h^{\prime \prime}\left(p_{6}\right)-h^{\prime}\left(p_{6}\right)}
$$

može se naći maseni protok tečnosti koja utiče u zagrejač ZVP 6:

$$
m_{c 7}=\left(1-x_{6, u l}\right)\left(m_{b}+m_{7, i z}\right)
$$

Pored ovoga, u zagrejaču ZVP 6 nastaje kondenzat sa masenim protokom:

$$
m_{c 6}=\frac{Q_{6}}{h^{\prime \prime}\left(p_{6}\right)-h^{\prime}\left(p_{6}\right)}
$$

tako da je ukupan protok kroz kondenzatnu pumpu:

$$
m_{p}=m_{c 7}+m_{c 6}
$$

Gore izloženi merematički model koji se sastoji od Sistema sa $10^{*}$ BrojNoda+4 diferencijalnih jednačina prvog reda rešen je numerički primenom metode Runge-Kutta za zadate početne uslove.

\section{REZULTATI}

Korišćenjem razvijenog modela određen je potencijal za povećanje snage turbine u okviru primarne/sekundarne regulacije. U tu svrhu modeliran je sledeći scenario. Protok u ECO1A se u toku 15 s povećava sa $25 \%$ na $40 \%$ protoka napojne vode dovedene isparivaču. Sledstveno, protok napojne vode kroz ZVP se smanjuje, tako da kroz jednu granu ZVP maseni protok napojne vode pada sa $210 \mathrm{~kg} / \mathrm{s}$ na $165 \mathrm{~kg} / \mathrm{s}$. Smanjenje protoka počinje u vremenskom trenutku $t=100$ s i odvija se po linearnom zakonu. Glavni cilj sprovedenog modeliranja je bio da se odrede sledeće veličine: (i) smanjenje masenog protoka pare na turbinskim oduzimanjima, tj. povećanje protoka pare kroz turbine i (ii) promena temperature materijala zagrejača visokog pritska sa vremenom.

U daljem tekstu prikazani su dobijeni rezultati. Napominje se da je pri prikazu rezultata korišćena sledeća notacija: stacionarno stanje pre početka prelaznog stanja obeleženo je indeksom $s$, a stacionarno stanje po završetku prelaznog stanja obeleženo je indeksom e.

Usled smanjenja protoka napojne vode snaga svih ZVP pada za oko 20\% (vidi Sliku 3). Smanjeno odvođenje toplote napojnom vodom vodi ka smanjenju intenziteta kondenzacije usled čega se pritisak u ZVP 6 povećava za 0,13bar (vidi Sliku 4-levo). Kao posledica ovog povećanja pritiska, dotok pare u zagrejač ZVP 6bis se smanjuje za $\Delta m_{b}=2.645 \mathrm{~kg} / \mathrm{s}$ (vidi Sliku 4-desno). Pošto postoje dve linije ZVP, ovo znači da se protok na oduzimanju turbine srednjeg pritiska smanjuje za $\Delta m_{0, T S P}=2 \Delta m_{b}=5,290 \mathrm{~kg} / \mathrm{s}$

Pritisak u ZVP 7 se, takodje zbog smanjenog odvođenja toplote i slabije kondenzacije, povećava za 0,498bar (vidi Sliku 5-levo) usled čega se maseni protok na ulazu u ZVP 7 smanjuje za $\Delta m_{7 u l}=3.518 \mathrm{~kg} / \mathrm{s}$ (vidi Sliku 5-desno). 
Kako postoje dve grane zagrejača, protok na oduzimanju iza turbine visokog pritiska je smanjen za $\Delta m_{0, T V P=}$ $2 \Delta m_{7 \mathrm{ul}}=7.036 \mathrm{~kg} / \mathrm{s}$.

Usled gore pomenutih smanjenih oduzimanja pare povećava se protok pare kroz turbinu srednjeg i turbinu niskog pritiska, a time i njihova snaga za oko 10MW kao što je prikazano na Slici 6.

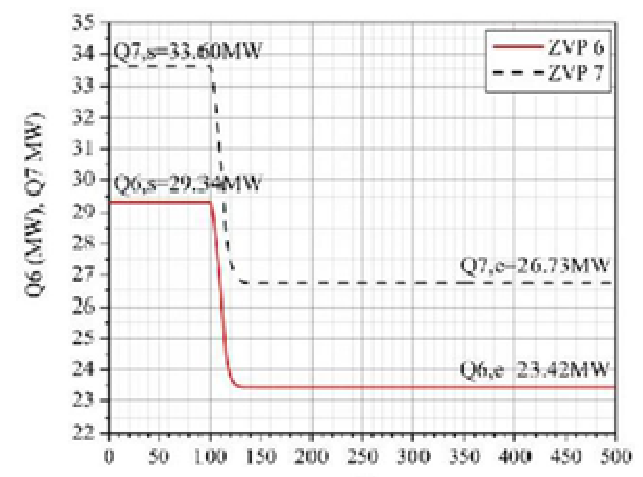

$\mathrm{t}(\mathrm{s})$

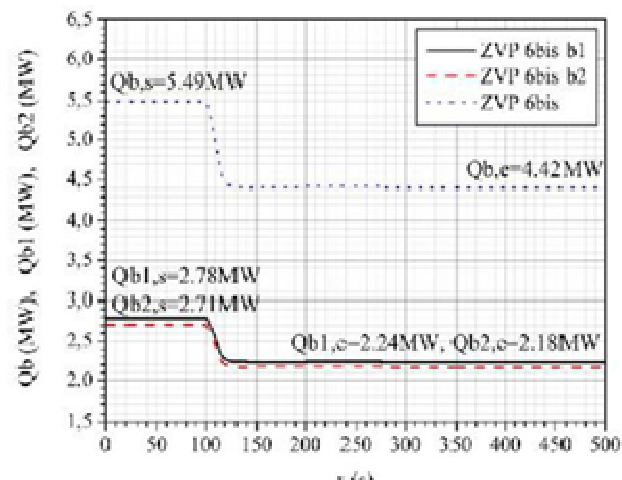

t(s)

Slika 3: Promena snage zagrejača visokog pritiska izazvana smanjenjem protoka napojne vode

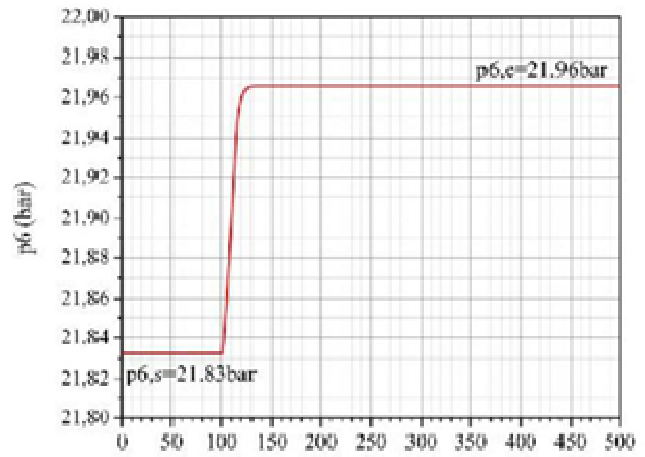

$1(\mathrm{~s})$

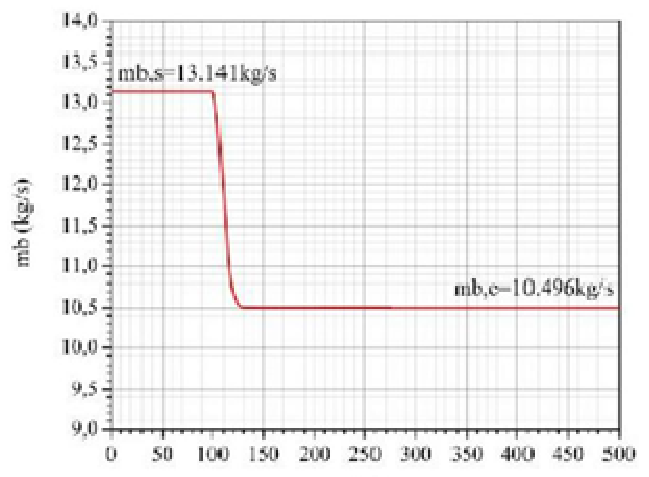

4 (s)

Slika 4: Porast pritiska na parnoj strani zagrejača ZVP 6 usled smanjenja protoka napojne vode (levo) i posledično smanjenje protoka pare kroz zagrejač ZVP 6bis (desno)
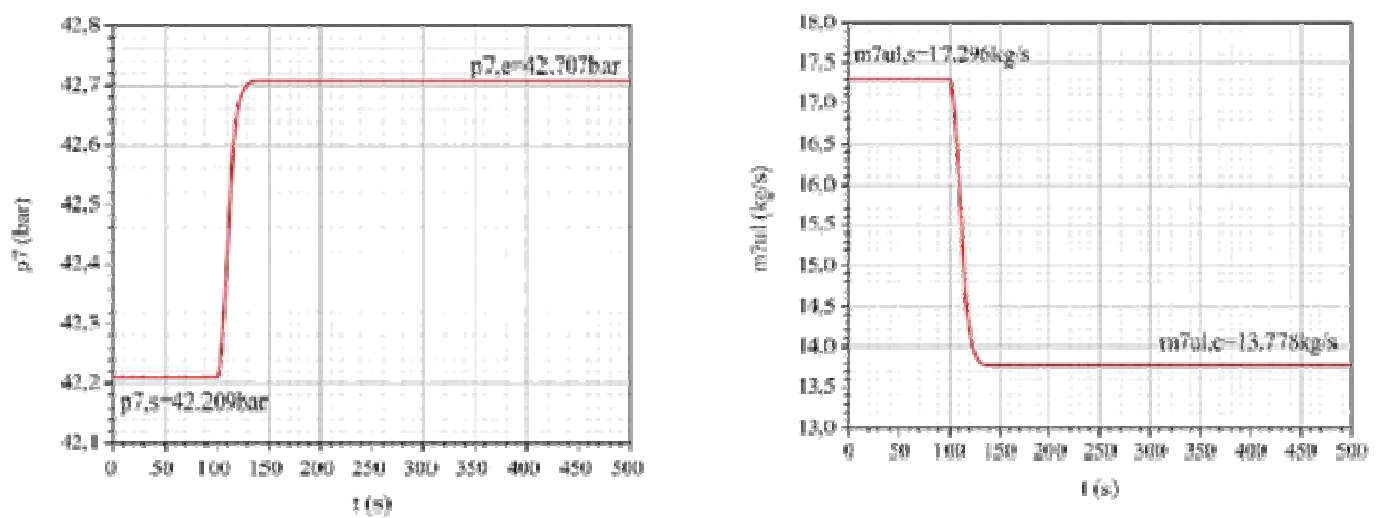

Slika 5: Porast pritiska na parnoj strani zagrejača ZVP 7 usled smanjenja protoka napojne vode (levo) i posledično smanjenje protoka pare kroz zagrejač ZVP 7 (desno) 

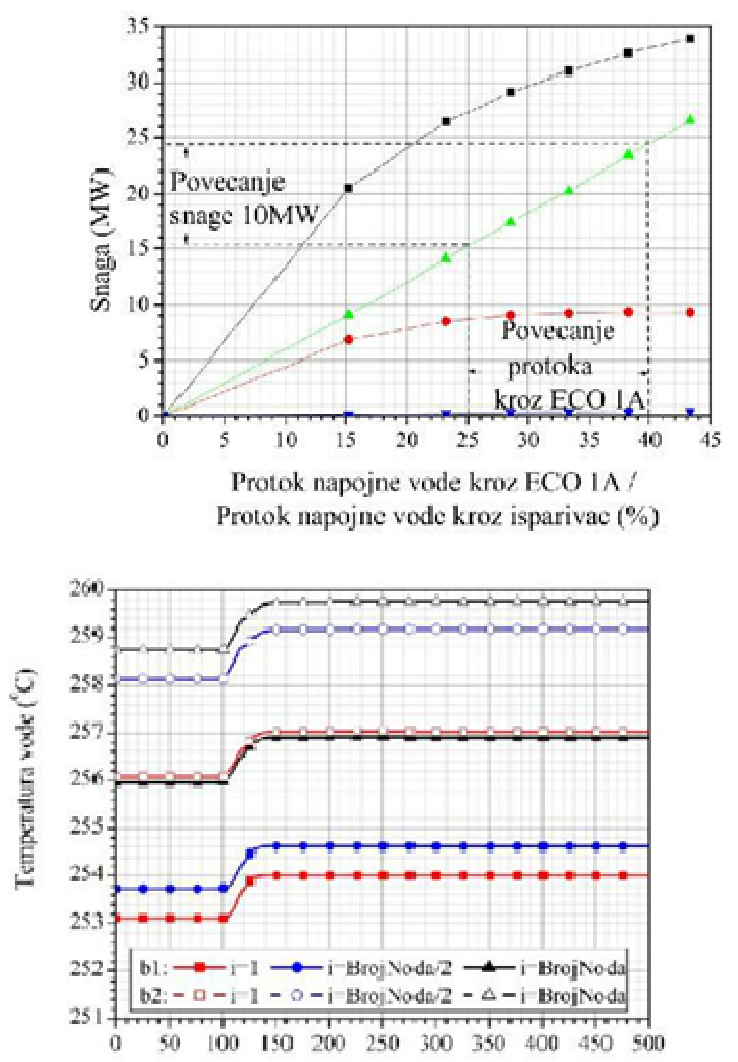

i(s)
Slika 6. Porast snage Bloka B1/ Bloka B2 usled povećanja protoka kroz ekonomajzer ECO $1 \mathrm{~A}$.

\begin{tabular}{l}
\hline Legenda uz Sliku 6: \\
- iskorišćena otpadna toplota dimnih gasova \\
- povećanje električne snage usled povećane \\
efikasnosti bloka B1/B2 \\
ukupno povećanje električne snage \\
povećanje električne snage usled smanjenja \\
pada pritiska napojne vode
\end{tabular}

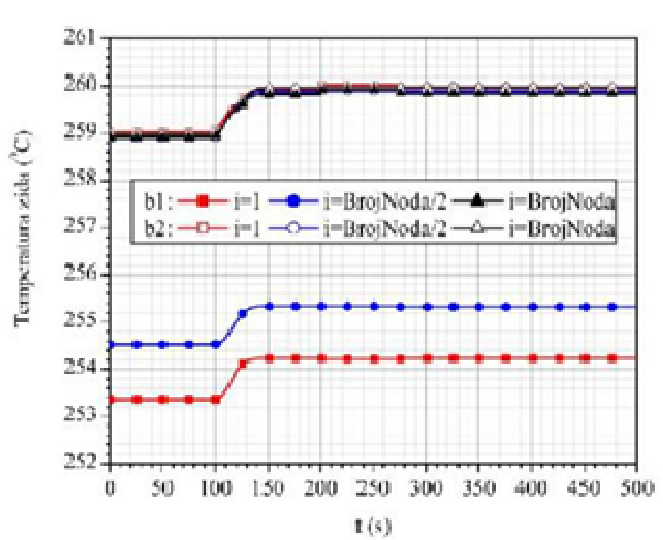

Slika 7: Porast temperature napojne vode (levo) i zida cevi (desno) u delovima b1 i b2 zagrejača ZVP 6bis usled smanjenja protoka napojne vode

Brzina promene temperature zida tokom prelaznog stanja je najviša u zagrejačima ZVP 6 i ZVP 7 i to u ulaznoj kontrolnoj zapremini (i=1): za ZVP $\quad 6, \quad d T_{w 6, i=1} / d t=5,6^{\circ} \mathrm{C} / \mathrm{min}$, a za ZVP $7, \quad d T_{w 7, i=1} / d t=6,4^{\circ} \mathrm{C} / \mathrm{min}$. Povećanje temperature zida u oba dela b1 i b2 zagrejača je, takodje, evidentno (vidi Sliku 7-desno). U delu b2, gde se odvija istosmerno strujanje vode i pare, temperatura zida se veoma malo menja duž cevi. Uticaj smera strujanja pare značajno utiče i na temperaturu vode (vidi Sliku 7-levo): veći porast temperature vode ostvaruje se za deo b1 (suprotnosmerno strujanje) u izlaznoj, a za deo b2 (istosmerno strujanje) u ulaznoj polovini.

Dobijeni rezultati pokazuju da su u zagrejaču ZVP 6bis razlike temperatura izmedju napojne vode i zida cevi dva reda veličine niže od razlike temperatura izmedju pregrejane pare i zida (na primer, u stacionarnom stanju pre početka prelaznog režima razlika temperature zida i vode je: $T_{\text {wb1,i=BrojNoda- }} T_{\text {vb1,i=BrojNoda }}=2,95^{\circ} \mathrm{C}$ i $T_{\text {wb2,i=BrojNoda- }}$ $T_{\text {vb2, } i=\text { BrojNoda }}=0,24^{\circ} \mathrm{C}$, a razlika temperature pare i zida: $T_{p b 1, i=B r o j N o d a}-T_{\text {wb1,i=BrojNoda }}=189,42^{\circ} \mathrm{C}$ i $T_{p b 2, i=B r o j N o d a-}$ $T_{\text {wb2,i=Brojoda }}=16,60^{\circ} \mathrm{C}$ ). Ovo je posledica veoma različitih vrednosti koeficijenta prelaza toplote sa vodene i sa parne strane: $\alpha_{v b 1} \sim \alpha_{v b 2} \sim 21830 W /\left(m^{2} K\right)$, dok su $\alpha_{p b 1} \sim 231 W /\left(m^{2} K\right)$ i $\alpha_{p b 2} \sim 247 W /\left(m^{2} K\right)$. Sa druge strane, u ZVP 6 i ZVP 7 vrednosti koeficijenta prelaza toplote sa parne i vodene strane su slične: u ZVP $6 a_{p 6} \sim 8417 W /\left(m^{2} K\right)$ i $a_{v 6} \sim 7353 \mathrm{~W} /\left(m^{2} \mathrm{~K}\right)$, dok u ZVP $7 \alpha_{p 7} \sim 9154 \mathrm{~W} /\left(m^{2} \mathrm{~K}\right)$ i $\alpha_{v 7} \sim 7739 \mathrm{~W} /\left(m^{2} \mathrm{~K}\right)$. 


\section{ZAKLJUČAK}

U ovom radu su prikazani rezultati numeričke simulacije promene snage parnih blokova B1 i B2 sa promenom protoka napojne vode kroz dodatni ekonomajzer. Modelirano je zagrevanje napojne vode u zagrejačima visokog pritiska (ZVP), oduzimanje pare koja se iz parne turbine vodi ka ZVP i promena snage turbine shodno promeni protoka pare. Dobijeni rezultati pokazuju da smanjena kondenzacija dovodi do povećanja pritisaka na parnoj strani ZVP, što smanjuje protoke oduzimanja pare iz turbine srednjeg pritiska i iza turbine visokog pritiska. Usled smanjenog oduzimanja, povećava se protok kroz turbinu srednjeg i turbinu niskog pritiska, a ukupna snaga turbine se povećava za oko 10MW. Brzina promene temperature metala cevi ZVP je u dozvoljenim granicama. Dobijeni rezultati pokazuju da se promenom protoka napojne vode kroz dodatni ekonomajzer može ostvariti primarna i sekundarna regulacija snage blokova, pri čemu se ne menjaju pritisak, temperatura i protok sveže pare.

\section{REFERENCE}

[1] V.D. Stevanovic, T. Wala, S. Muszynski, M. Milic and M. Jovanovic, "Efficiency and power upgrade by an additional high pressure economizer installation at an aged 620 MWe lignite-fired power plant." Energy, br. 66, 2014, str. 907-918. doi: 10.1016/j.energy.2014.01.001

[2] P. Konstantin, Praxisbuch Energiewirtschaft. Berlin, Heidelberg: Springer Nature. 2013. doi: 10.1007/978-3642-37265-0

[3] D. Rumpel, "Towards an Improved Coordination of Power Plant and Power System Control", u Power Systems: Modelling and Control Applications. Elsevier BV. 1989, str. 1-8 1st Edition, Selected Papers from IFAC Symposium, Brus-sels, 5-8 September. doi: 10.1016/b978-0-08-036135-2.50011-9

[4] V.P. Isachenko, V.A. Osipova and A.S. Sukomel, Heat Transfer. Moscow: MIR Publishers. 1977. (engleski prevod).

[5] S. Kakac, R.K. Shah and W. Aung, Handbook of Single-Phase Convective Heat Transfer. John Wiley and Sons. 1987.

[6] M.A. Miheev and I.M. Miheeva, Osnove prenosa toplote. Moskva: Energia. 1973. (na ruskom).

Paper submitted: $\quad$ May 20, 2016

Paper revised: July 30, 2016

Paper accepted: $\quad$ August 27, 2016
Copyrights ${ }^{\odot} 2017$ Society of Thermal Engineers of Serbia Published by the VINCA Institute of Nuclear Sciences, Belgrade, Serbia This is an open access article distributed under the CC BY-NC-ND 4.0 terms and conditions 